\title{
Investigation of Subjective Thermal Sensation and Its Relationship with Stress, Anxiety, Depression and Cognitive Function of Students of Isfahan University of Medical Sciences
}

\author{
Samira Barakat $^{1 \text { (D), Habibollah Dehghan }}{ }^{\text {(D) }}$, Hossein Ebrahimi ${ }^{\text {(iD), Behnam Moradi }}{ }^{3 *}$
}

1. MSc, Department of Occupational Health and Safety Engineering, School of Public Health, Isfahan University of Medical Sciences, Isfahan, Iran

2. Associate Professor, Department of Occupational Health Engineering, School of Public Health, Isfahan University of Medical Sciences, Isfahan, Iran

3. MSc, Department of Health, Safety and Environment, School of Public Health and Safety, Shahid Beheshti University of Medical Sciences, Tehran, Iran

\section{Article Info \\ Received: 2021/07/02; \\ Accepted: 2021/09/03; \\ ePublished: 2021/09/21 \\ 10.30699/jergon.9.2.95 \\ Use your device to scan and read the article online

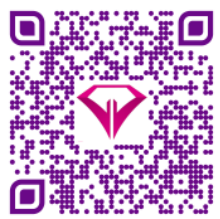

Corresponding Author

Behnam Moradi

MSc, Department of Health,

Safety and Environment,

School of Public Health and

Safety, Shahid Beheshti

University of Medical

Sciences, Tehran, Iran

Email:

b.moradi@sbmu.ac.ir

\section{ABSTRACT}

Background and Objectives: Thermal sensation is not a direct sense of air temperature but is related to people's feelings, sensory experience and psychological phenomenon, which can affect their performance, productivity, attitude and sense of satisfaction. The aim of this study was to determine the subjective thermal sensation and its relationship with stress, anxiety, depression and students' cognitive function.

Methods: This study was descriptive-analytical and was performed on 167 male students of Isfahan University of Medical Sciences. Students' subjective thermal sensation was measured on a seven-point scale and ambient temperature and humidity were measured in each student's room. The DASS-42 questionnaire was used to measure stress and anxiety and the "Reaction Timer" device was used to measure the cognitive function. The collected data were analyzed by SPSS software version 20 .

Results: Students' stress, anxiety and depression were $40 \%, 47.3 \%$ and $41.3 \%$, respectively. The mean temperature of the dormitory was $20.326^{\circ} \mathrm{C}$, the mean relative humidity was $56.78 \%$ and the subjective thermal sensation of $29.9 \%$ of the students were neutral from the ambient temperature. There was a significant relationship between students' subjective thermal sensation and stress, anxiety and mean diagnostic reaction time, color selection, sound selection, number of errors in the diagnostic section and sound selection.

Conclusion: Students' subjective sensation of ambient temperature was obtained as a very important and influential factor because in addition to affecting stress and anxiety, it also had a significant effect on their time of diagnostic reaction and selective.

Keywords: Subjective thermal sensation, Stress, anxiety, Depression, Reaction time

Copyright $(\mathcal{C}$ 2021, This is an original open-access article distributed under the terms of the Creative Commons Attribution-noncommercial 4.0 International License which permits copy and redistribute of the material just in noncommercial usages with proper citation.

How to Cite This Article:

Barakat S, Dehghan H, Ebrahimi H, Moradi B. Investigation of Subjective Thermal Sensation and Its Relationship with Stress, Anxiety, Depression and Cognitive Function of Students of Isfahan University of Medical Sciences. Iran J Ergon. 2021; 9(2):95-106 


\section{Extended Abstract}

\section{Introduction}

Thermal sensation is not a direct sense of air temperature but is related to people's feelings, sensory experience, and psychological phenomenon, which can affect their performance, productivity, attitude, and sense of satisfaction. This study aimed to determine the subjective thermal sensation and its relationship with stress, anxiety, depression, and students' cognitive function.

\section{Methods}

This study was descriptive-analytical and was performed on 167 male students of Isfahan University of Medical Sciences. Students' subjective thermal sensation was measured on a sevenpoint scale, and ambient temperature and humidity were measured in each student's room. The DASS-42 questionnaire was used to measure stress and anxiety, and the "Reaction Timer" device was used to measure cognitive function. The collected data were analyzed by SPSS software version 20 (SPSS Inc., Chicago, Ill., USA).

\section{Results}

Students' stress, anxiety, and depression were $40 \%, 47.3 \%$, and $41.3 \%$, respectively. The mean temperature of the dormitory was $20.326^{\circ} \mathrm{C}$, the mean relative humidity was $56.78 \%$, and the subjective thermal sensation of $29.9 \%$ of the students was neutral from the ambient temperature. There was a significant relationship between students' subjective thermal sensation and stress, anxiety and mean diagnostic reaction time, color selection, sound selection, number of errors in the diagnostic section, and sound selection.

\section{Discussion}

This study aimed to determine the feeling of thermal sensation and its relationship with stress, anxiety, depression, and cognitive function in medical students. Findings showed that the average ambient temperature of the dormitory was $20.326^{\circ} \mathrm{C}$, the average relative humidity was $56.78 \%$, and the highest temperature sensation of students was obtained from the ambient temperature on a neutral scale, which is consistent with the results of Khan and Pao study. They reported that in areas with tropical climates, high humidity levels lead people to a positive degree of heat sensation in summer, while in winter, people are more inclined to neutral and stable conditions [20].

Students' mean scores of stress, anxiety, and depression were $10.1 \pm 6.6,8.8 \pm 7.6$, and 9.4 \pm 7.7 , respectively. $40 \%$ of students had stress at different levels (mild, moderate, severe and very severe). Also, $47.3 \%$ and $41.3 \%$ of students had anxiety and depression at different levels, respectively. Fawzy and Hamed also reported on the level of stress, anxiety, and depression of students that more than half of the study population are exposed to psychological traumatic factors, and students have $59.9 \%$ stress, $73 \%$ anxiety, and $65 \%$ depression and the average score of stress, anxiety, and depression were 11.41, 8.02 and 97.8, respectively [21]. Wahed and Hassan showed that the rate of stress, anxiety, and depression of students at different levels are $62.4 \%, 64.3 \%$, and $60.8 \%$, respectively [22]. In this study, less than $50 \%$ of students had stress, anxiety, and depression; While in the studies mentioned, more than $50 \%$ of students had stress, anxiety, and depression. Probably the reason for the difference between the results of the present study and other studies is that the studies of Fawzy, Hamed, Wahed and Hassan examined the levels of stress, anxiety and depression in both men and women; While in the present study, only male students in all fields and levels of study of the University of Medical Sciences were investigated. Nevertheless, this level of stress, anxiety, and depression is high in students. Researchers have found that stress and anxiety in students can have a variety of causes that can be related to age, special social situations, economic conditions, environmental conditions, entering a new environment, academic problems, decreased interest in the field of study, competition with other students and more importantly, he mentioned the fear of the job future [14, 23]. Bayram and Bilgel stated that the prevalence of stress, anxiety and depression among students is worrying and requires 
the implementation of primary and secondary preventive measures with the development of appropriate support services for this group of people in the community [24]. Beiter et al. reported that the prevalence of stress, anxiety, and depression among students indicates a lack of mental health. Universities should constantly assess students' mental health and have appropriate plans to ensure mental health and solve their problems [23].

Students' thermal sensation was significantly correlated with stress and anxiety and negatively correlated. A similar study was not found in this area, but this conclusion is probably due to the fact that the student's thermal sensation is both an individual and a mental factor and an environmental factor. In the meantime, each person, according to the temperature and sensory conditions he has from the ambient temperature, causes a different mental perception of his ambient temperature. Since the students' accommodation was in rooms with an approximate area of $12-18 \mathrm{~m} 2$ and windows, the average ratio of window area to floor area was calculated to be 0.093 and the dormitory fan coil heating system had central control in winter. If a person felt hot, he could not adjust the temperature of his room to his liking; Therefore, it caused the student to feel positive heat in winter on a positive scale, all of which caused the student to be unable and dissatisfied to regulate the desired temperature of his environment, and therefore students' feeling of heat had a significant relationship with stress and anxiety [25].

Mean diagnostic response time, color selection, sound selection, number of errors in the diagnostic section and number of errors in the sound selection section were significantly associated with subjective sensation of ambient temperature; the neutral thermal sensation was observed in the reaction time (diagnostic and selective) appropriately and without error in students, and when their thermal sensation was on a positive scale (hot, warm and slightly warm) and a negative scale (cold, cool and slightly cool), time Their response in the diagnostic and selective sections was increased and errors in the diagnostic and selective sections were observed, which is consistent with the results of the study of Hancock et al. [26]. Heat exposure is effective on the reaction time test, Pilcher, Nadler, and Busch reported. Exposure to a hot environment also affects the performance of tasks such as learning, reasoning and working memory; While tasks that require accuracy, attention and perception have a negative effect on the performance of such tasks in the face of a hot environment [27].

In the present study, simple reaction time had no significant relationship with thermal sensation; Perhaps because the students' thermal sensation was assessed from the ambient temperature. Also, since people's feelings of ambient temperature are different, in this study, no significant relationship was found between heat feeling and reaction time. One study found that exposure to hot environments had little effect on simple tasks such as reaction time; While exposure to a hot environment has a profound effect on complex tasks such as care, follow-up, learning, and multiple tasks [30].

\section{Conclusion}

Students' subjective sensation of ambient temperature was obtained as a critical and influential factor because, in addition to affecting stress and anxiety, it also had a significant effect on their time of diagnostic reaction and selection.

\section{Acknowledgement}

The present study is taken from research project No. 195180 approved by Isfahan University of Medical Sciences. The authors sincerely thank the Vice Chancellor for Research and Technology, who assisted us in conducting this research.

\section{Conflict of Interest}

The authors declared no conflict of interest. 
بررسى احساس حرارتى ذهنى و ارتباط آن با استرس، اضطراب، افسردىى و عملكرد شناختى دانشجويان

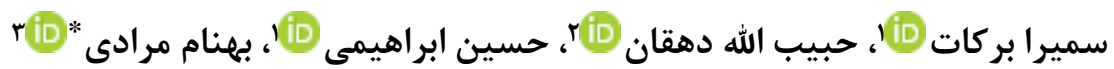

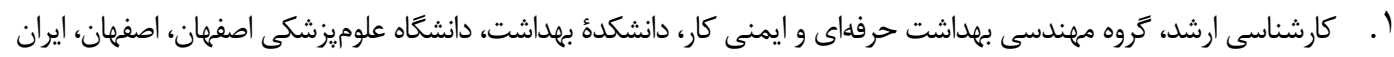

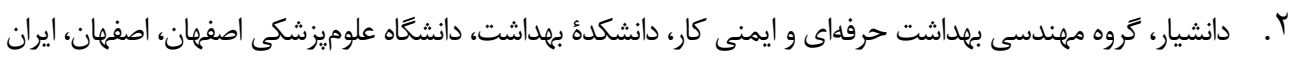

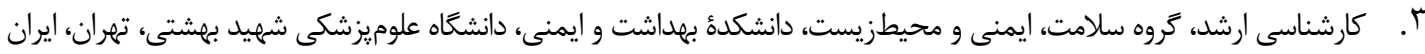

خلاصه

زمينه و هدف: احساس حرارتى حسى مستقيم از درجأ حرارت هوا نيست، بلكه به جَكَونكى احساس افراد

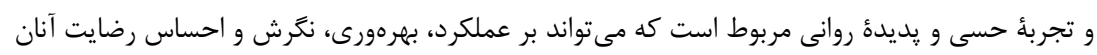

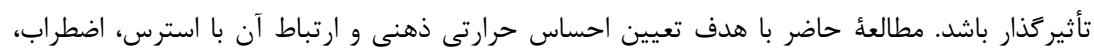

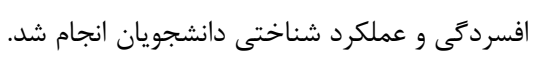

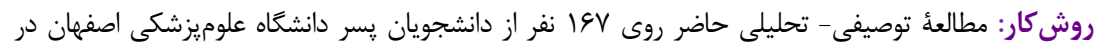

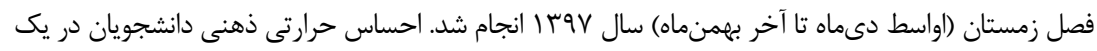

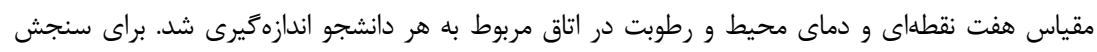

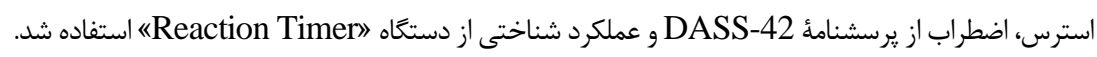

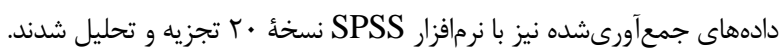

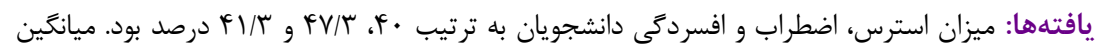

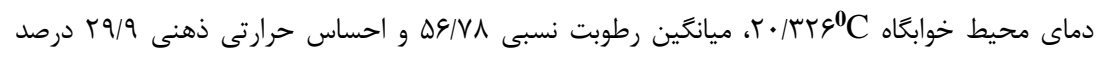

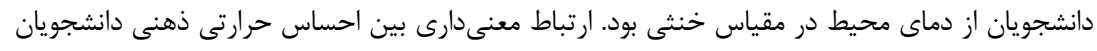

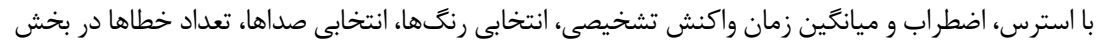

تشخيصى و انتخابى صدا به دست آمد.

نتيجهََيرى: زمانى كه احساس حرارتى ذهنى دانشجويان فاقد احساس حرارتى خنثى باشد و در سطوح

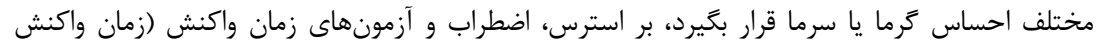

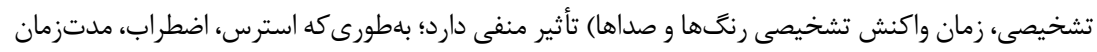

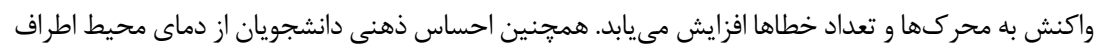

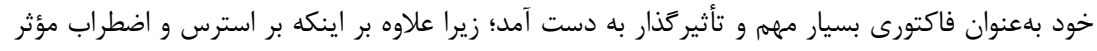

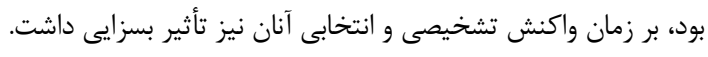
كليدوازهها: احساس حرارتى ذهنى، استرس، اضطراب، افسردىى، زمان واكنش

$$
\begin{aligned}
& \text { اطلاعات مقاله } \\
& \text { دريافت: } \\
& \text { يذيرش: }
\end{aligned}
$$

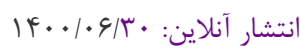

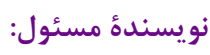

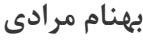

$$
\begin{aligned}
& \text { كارشناسى ارشد، گروه سلامت، ايمنى و }
\end{aligned}
$$

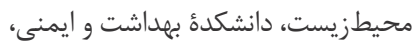

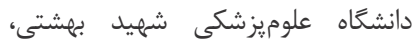

$$
\begin{aligned}
& \text { تهران، ايران }
\end{aligned}
$$

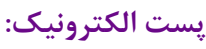

b.moradi@sbmu.ac.ir

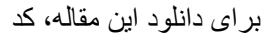
زير را با موبايل خود اسكن مقانك كنيد.

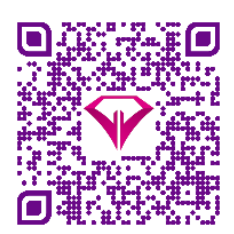

كبىرايت (C) مجله اركونومى؛ دسترسى آزاد؛

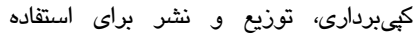
غيرتجارى با ذكر منبع آزاد است.

مقدمه

سيستمهاى گرمايشى و سرمايشى ساختمان ها براى افراد مربوط در دسترس نيست. به نظر مىرسد شرايط آب و هوايى خاص

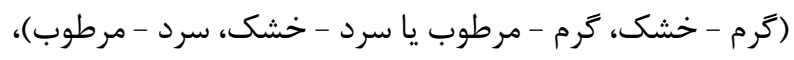
اثرى منفى بر بهرهورى نيروى كار دارد. بهرهورى در نتيجة ناراحتى و نارضايتى مرتبط با تغييرات قابلتوجه حرارتى محيط كاهش مىيابد؛ براى مثال، تابش زياد نور خورشيد سبب
عوامل محيطى داخلى مانند دماى هواى داخل ساختمان

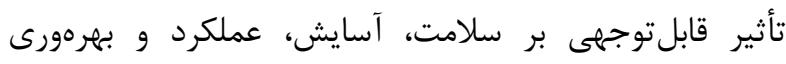

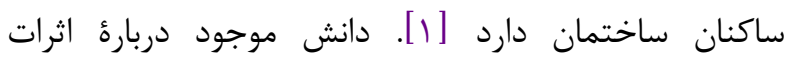
فيزيولوزيكى و روانى شرايط حرارتى ناكافى است و اطلاعات كافى براى مقابله با تأثير تغييرات حرارتى محيطى بر بر بهرهورى

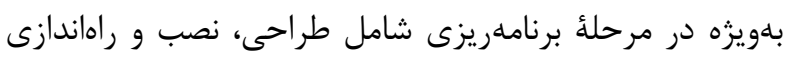


مشاهده كردند. آنها كاهش قابلتوجهى در دقت و تمركز به

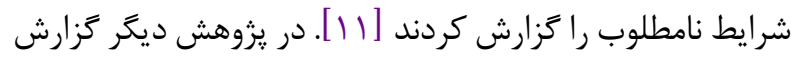
شد، فضاى آموزشى مكانى براى خواندن، نوشتن، مطالعهُ نقشهها

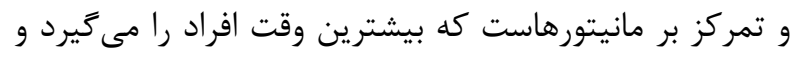

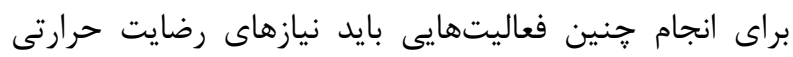

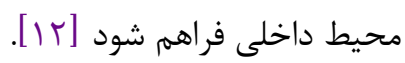

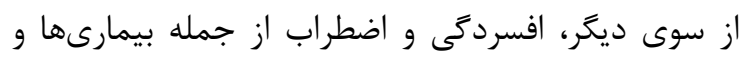

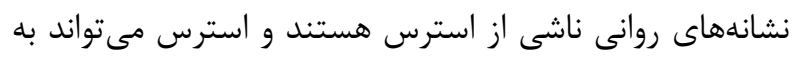

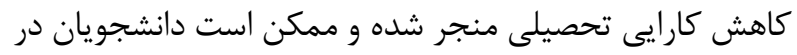

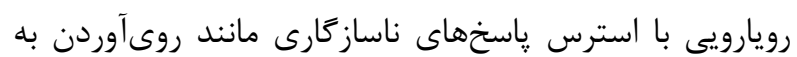

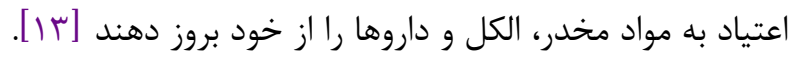

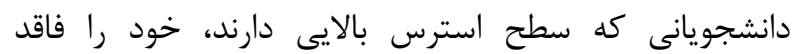

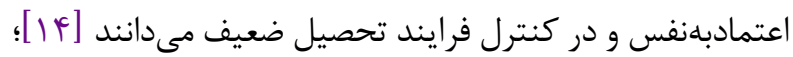

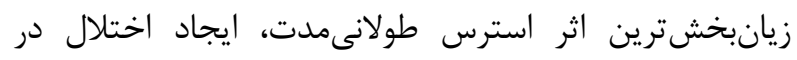

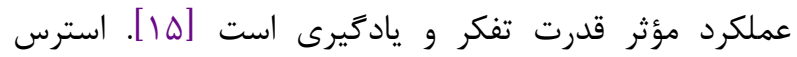
مى تواند به بروز بيمارى هاى جسمى و ورانى، اختلال در عملكرد

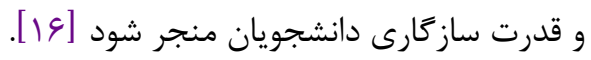

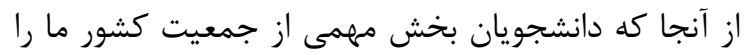
تشكيل مىدهند و هرساله بر تعداد آنان افزوده مىشود و و تعداد إنداد

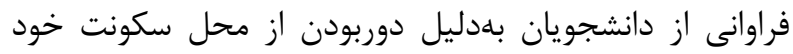

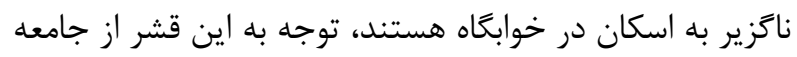

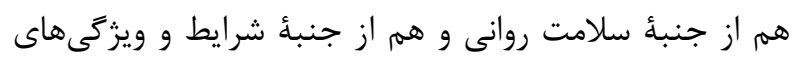

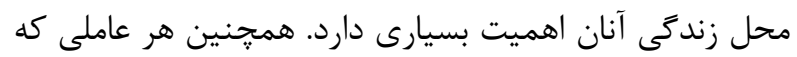

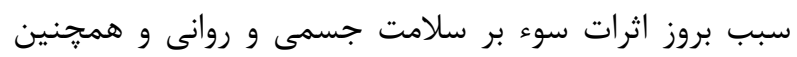

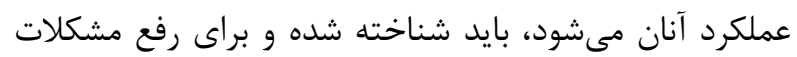

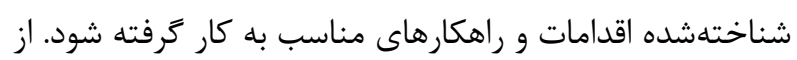

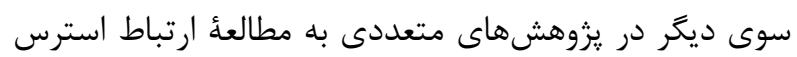

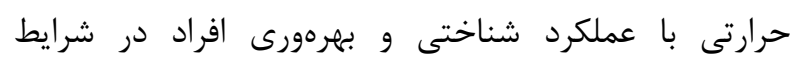

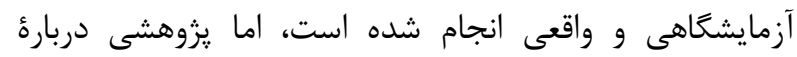
احساس حرارتى ذهنى افراد با ڤارامترهاى روانى (استرس،

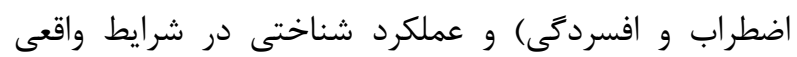

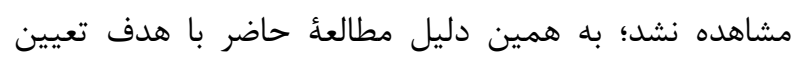

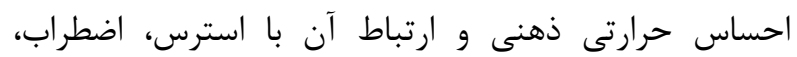
افسردىى و عملكرد شناختى دانشجويان انجام شد.

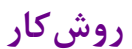

مطالعه حاضر توصيفى - تحليلى بود كه در فصل زمستان

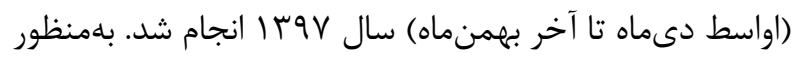

احساس خستخى در كار گران مىشود. همجنين كاركردن در آب و هواى بسيار ترم اثرات فيزيولوزيكى و روانى بر كاركران

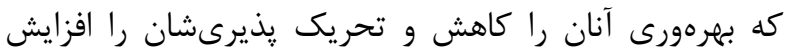

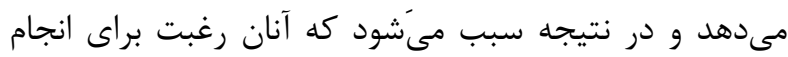
كارشان را از دست بدهند [r] محيط حرارتى مناسب، بهرهورى، احساس رضايت و رفاه

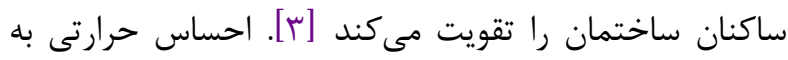

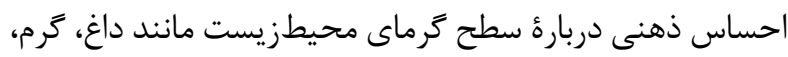

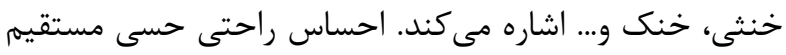

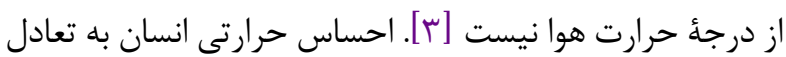

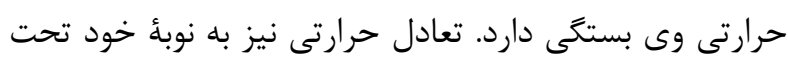

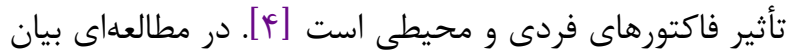

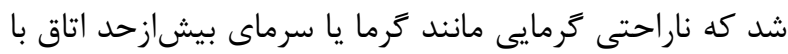

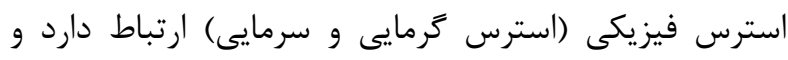

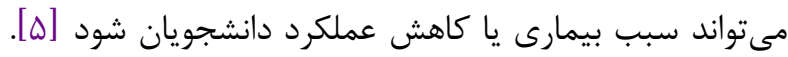
از اثرات منفى ناراحتى كرمايى در افراد مىتوان به افزايش

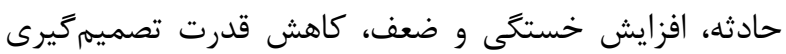

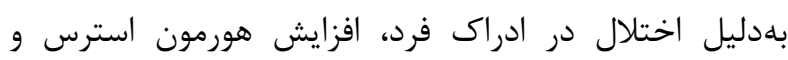

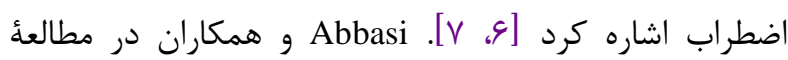

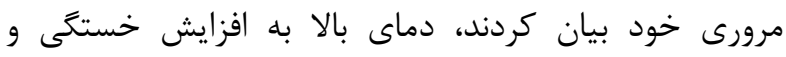

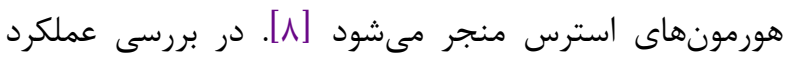

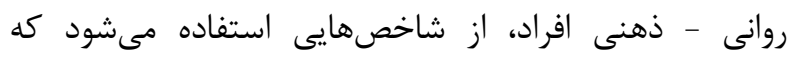

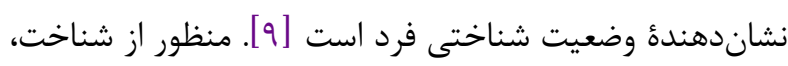

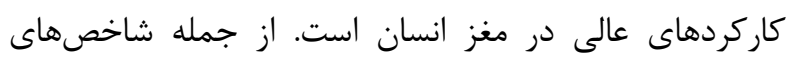

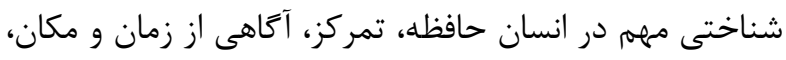

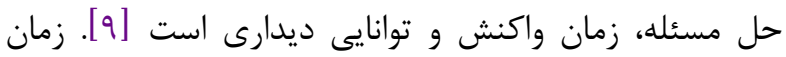
واكنش را مىتوان بهكمى روشهاى تجربى (دستكاههاى

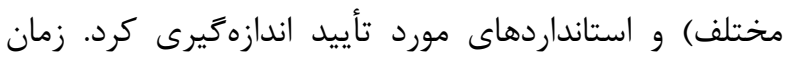
واكنش تحت تأثير جندين متغير شامل تمركز و توجه، عملكرد

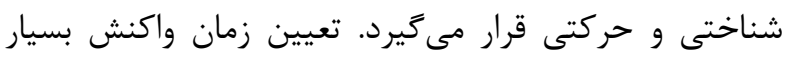

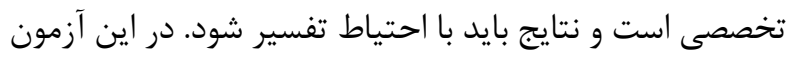

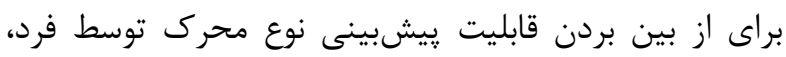

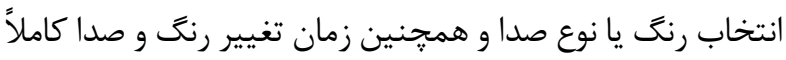

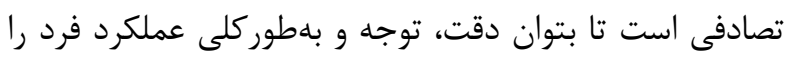

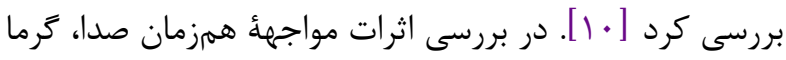

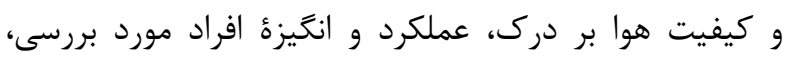
Balazova

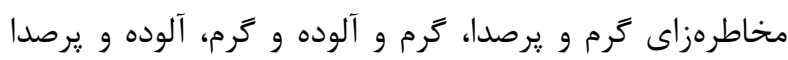


مرحلة سوم: در اين مرحله دما و رطوبت محيط با استفاده از دماسنج و رطوبتسنج ديجيتالى ) - TEMPERRATURE مدل HUMIDITY مد HTC-1) در محل اقامت دانشجو (اتاق

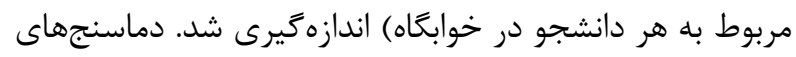

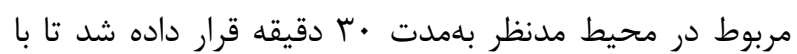
دماى محيط به تعادل برسد و سيس عدد مربوط به هر دماسنج و رطوبت سنج قرائت و ثبت شد.

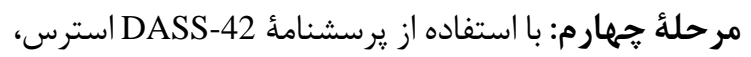
اضطراب و افسردىى دانشجويان بررسى شد. اين برسشنامه براى

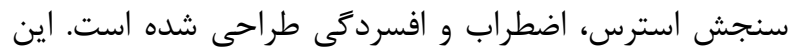
مقياسها در يك طيف ليكرت جهاردرجهاى نمرهكذارى شده

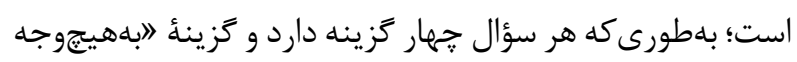
در مورد من درست نيسته، نمرئ صفر و تزينهُ "ابسيار زياد

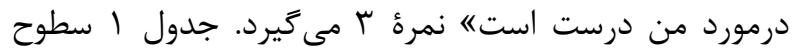

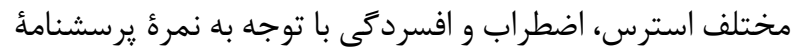

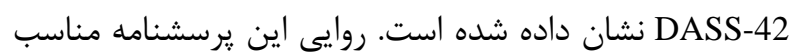

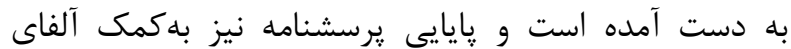

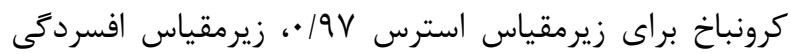

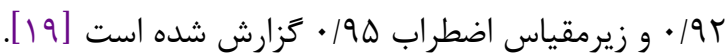

جمعآورى دادهها از روش نمونهَيرى تصادفى سيستماتيك

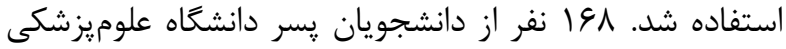
اصفهان با در نظر گرفتن معيار ورود به مطالعه، از قبيل نداشتن

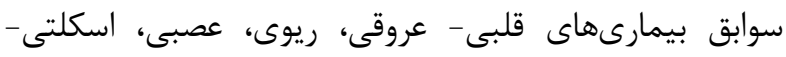

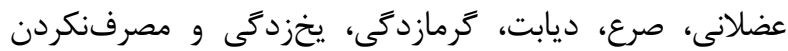

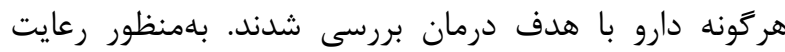

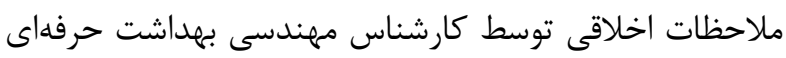
به افراد مورد بررسى درباره اهداف مطالعه توضيحاتى ارائه شد و تراتئ

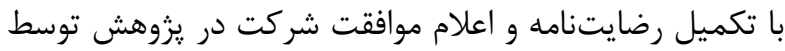

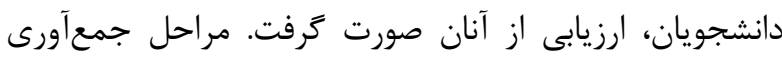

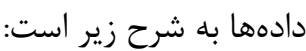

مرحلهُ اول: ابتدا :رسشنامة اطلاعات دموكرافيك شامل سن، قد، وزن، رشتأ تحصيلى و مقطع تحصيلى براى هر يك از افراد مورد بررسى تكميل شد. مرحلة دوم: براساس استاندارد ASHRAE براس ترديل تخدمين احساس حرارتى ذهنى از يك مقياس هفتنقطهاى استفاده شد. بدينصورت كه از دانشجويان خواسته شد احساس خود از از درجه

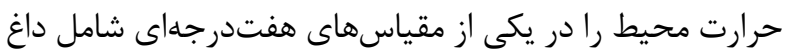

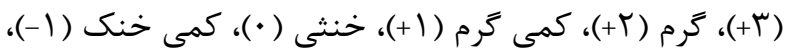

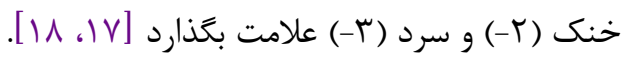

جدول ا. سطوح مختلف استرس، اضطراب و افسردكى را با توجه به نمره يرسشنامه DASS-42

\begin{tabular}{|c|c|c|c|}
\hline افسردَى & اضطراب & استرس & متغير \\
\hline & & & سطح \\
\hline$\cdot-9$ & $\cdot-V$ & $\cdot-9$ & طبيعى \\
\hline $1 \cdot-1 \mu$ & $1-9$ & $1 \cdot-1 r$ & خفيف \\
\hline $\mid Y-r$. & $1 \cdot-14$ & $\mid F-r$. & متوسط \\
\hline$r I-r V$ & $10-19$ & $r I-r V$ & شديد \\
\hline$-Y \Lambda$ & $-r$. & $-M F$ & خيلى شدي \\
\hline
\end{tabular}

هرتز (بم). با اين دستگاه مىتوان زمان واكنش را در جهار حالت

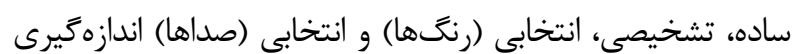

- مان واكنش ساده: زمانى كه دستگاه روى يك رنغ تنظيم

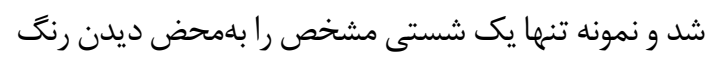
فشار مىداد و زمان واكنش ثبت مىشد، در اين بخش خطايى وجود نداشت.

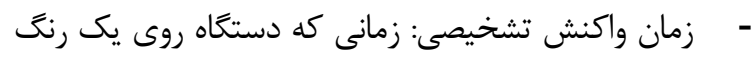

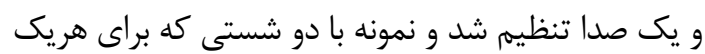

مرحلة ينجم: بررسى عملكرد شناختى دانشجويان با آزمون زمان واكنش توسط دستخاه Reaction Timer

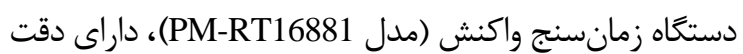
| • • • ثانيه است. اين دستخاه شامل يك جعبئ بزرى است كه تجهيزات و كليدهاى كنترل روى آن تعبيه شده و دو شستى كه با

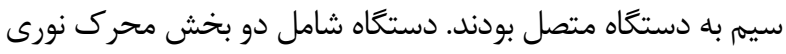
و صوتى كه محرك نورى از سه رنغ سبز و قرمز و آبى تشكيل مىشد و محرك صوتى، صداى بوق كوتاهى بود كه از لحاظ شدت و زمان قابل تنظيم است (r صدا با فر كانسهاى • • هرتز (زير) و 1 
Reaction Timer براى دانشجو تكرار و زمانهاى واكنش و تعداد خطاها ثبت مى آنشد.

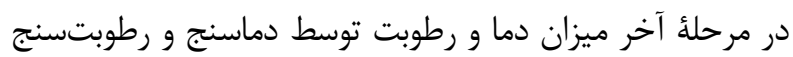

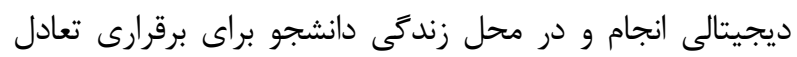

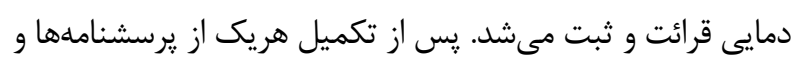

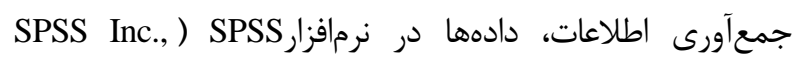

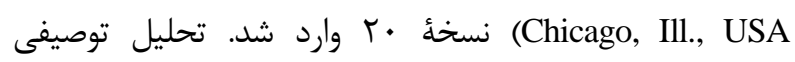
متغيرهاى كمى با استفاده از شاخصهاى ميانكين و انحراف معيار

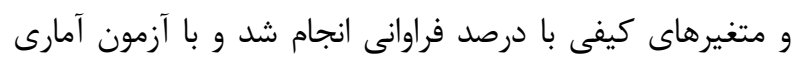
ضريب همبستخى ييرسون مورد تجزيه و تحليل آمارى قرار گرفت

\section{يافته ها}

در مطالعئ حاضر، $19 V$ نفر از دانشجويان پسر براى بررسى

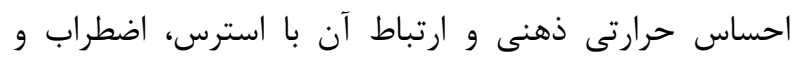

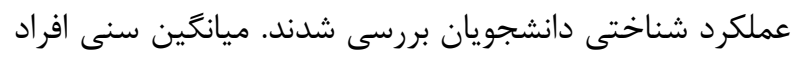

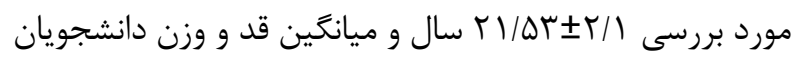

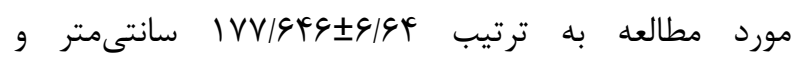

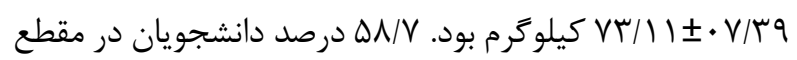

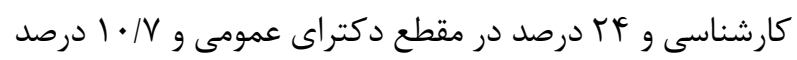
در مقطع كارشناسى ارشد مشغول به تحصيل بودند. ميانكين دماى محيط خوابكاه

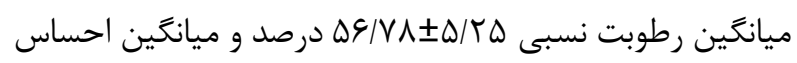

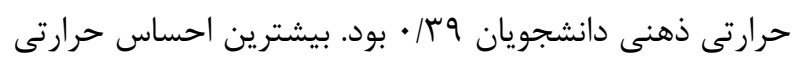

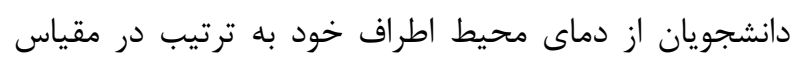

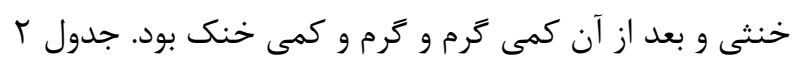

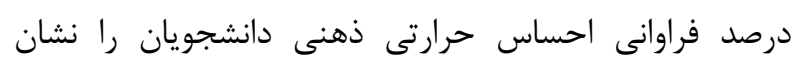

مى مهد.

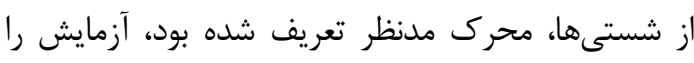
انجام مىداد كه در اين قسمت علاوه بر زمان واكنش، خطاها نيز ثبت مىشود.

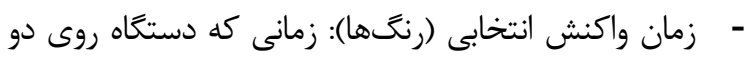

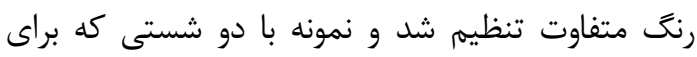

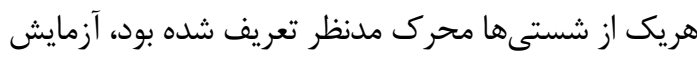

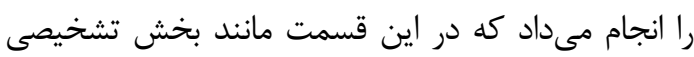

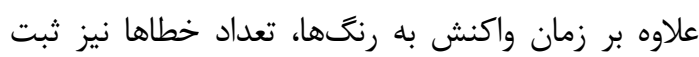

مىشد. زمان واكنش انتخابى (صداها): زمانى كه دستخاه روى دو

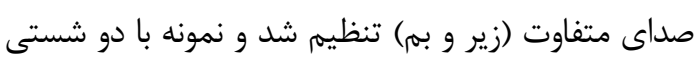

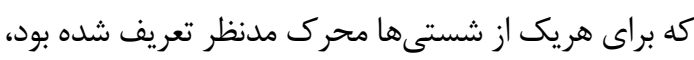

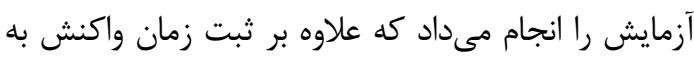
صداها، تعداد خطاها نيز ثبت مى شداند.

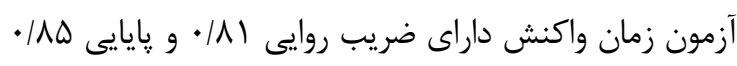

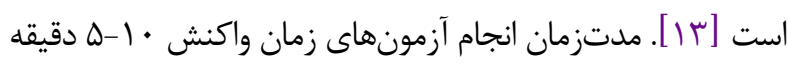

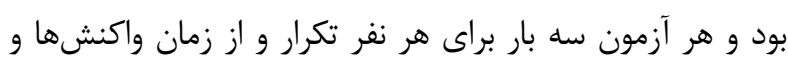

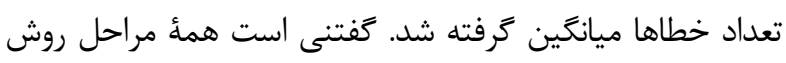

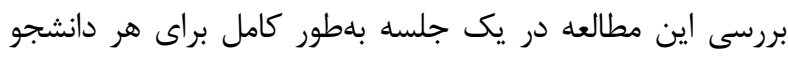

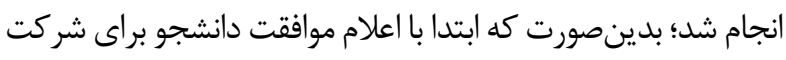

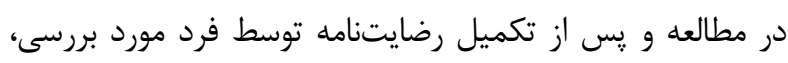

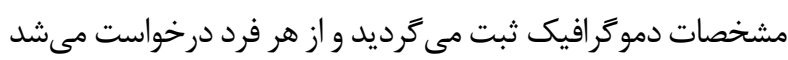

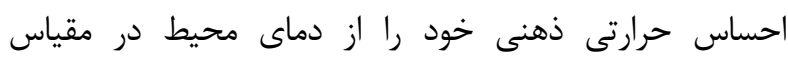

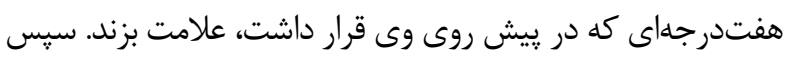

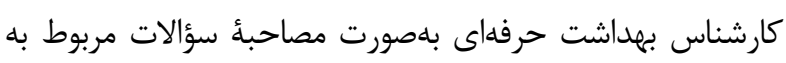

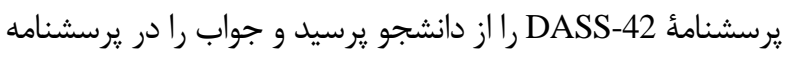

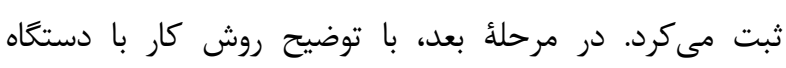

\begin{tabular}{|c|c|c|c|c|c|c|c|}
\hline سرد & خنك & كمى خنك & خنثى & كمى كرم & ترم & داغ & احساس حرارتى ذهنى \\
\hline $1 / 1$ & 4 & $10 / 9$ & $r q / q$ & re/ & $10 / 9$ & $f / \Lambda$ & درصد فراوانى \\
\hline
\end{tabular}

افسردگى (اضطراب و افسردگى طبيعى) بودند؛ درحالى كه 9/9

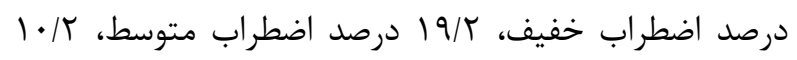
درصد اضطراب شديد و N/F درصد اضطراب خيلى شديد

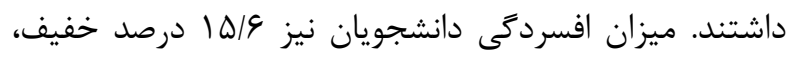
IV/F شديد بود.
با توجه به جدول ب، ميانگين نمره استرس در ميان دانشجويان

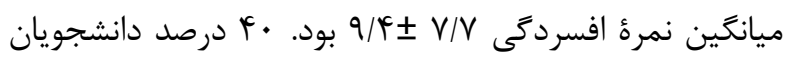

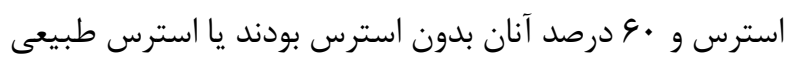
داشتند. ميزان استرس آنان در سطوح خفيف، متوسط، شديد و بدون

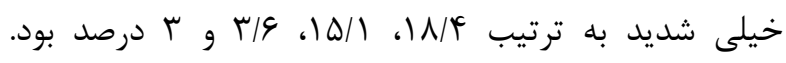
همجنين هY/V و DN/V درصد دانشجويان بدون اضطراب و 


\begin{tabular}{|c|c|c|c|c|c|c|}
\hline حداقل & حداكثر & انحراف معيار & ميانكين & درصد فراوانى (\%) & سطح متغير & متغير \\
\hline \multirow{5}{*}{ • } & \multirow{5}{*}{ 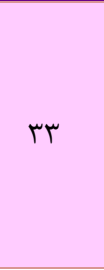 } & \multirow{5}{*}{$9 / 9$} & \multirow{5}{*}{$1 \cdot 11$} & 4. & طبيعى & \multirow{5}{*}{ استرس } \\
\hline & & & & $11 /\left.\right|^{k}$ & خفيف & \\
\hline & & & & $10 / 1$ & متوسط & \\
\hline & & & & r/s & شديد & \\
\hline & & & & r & خيلى شديد & \\
\hline \multirow{5}{*}{ · } & \multirow{5}{*}{ er } & \multirow{5}{*}{$V / 9$} & \multirow{5}{*}{$\Lambda / \Lambda$} & $\Delta T / V$ & طبيعى & \multirow{5}{*}{ اضطراب } \\
\hline & & & & $9 / 9$ & خفيف & \\
\hline & & & & $19 / 4$ & متوسط & \\
\hline & & & & $1 \cdot / r$ & شديد & \\
\hline & & & & $N / F$ & خيلى شديد & \\
\hline \multirow{5}{*}{. } & \multirow{5}{*}{ rv } & \multirow{5}{*}{$V / V$} & \multirow{5}{*}{$9 / 4$} & $\Delta \Lambda / V$ & طبيعى & \multirow{5}{*}{ افسردكى } \\
\hline & & & & $10 / 9$ & خفيف & \\
\hline & & & & $I V / F$ & متوسط & \\
\hline & & & & $r / 9$ & شديد & \\
\hline & & & & $f / r$ & خيلى شديد & \\
\hline
\end{tabular}

براساس جدول \& أ، ميانگين زمان واكنش تشخيصى (r)

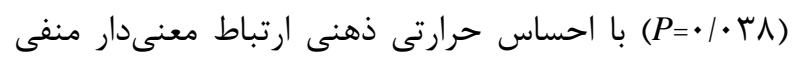

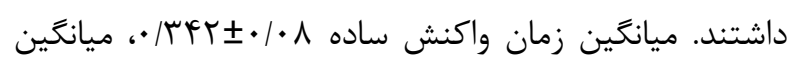

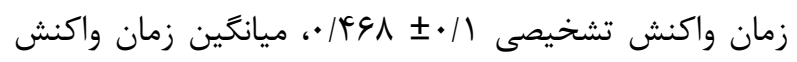

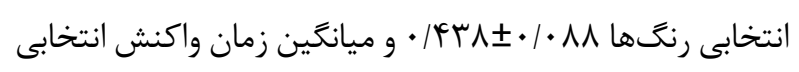

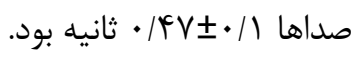

احساس حرارتى ذهنى دانشجويان با استرس (RVT) •- (TVT)

FV • F همبستخى منفى داشتند؛ به بيان ديخر زمانى كه احساس حرارتى ذهنى دانشجويان از مقدار خنثى فاصله مى در محدوده گرما يا سرما قرار مى گرفت، ميزان استرس و اضطى اضطراب آنها افزايش مىيافت؛ درحالى كه احساس حرارتى ذهنى باده

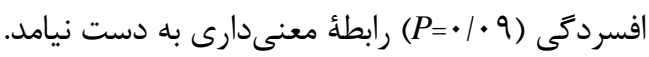

جدول F. ارتباط احساس حرارتى ذهنى با پارامترهاى زمان واكنش

\begin{tabular}{|c|c|c|c|c|c|c|}
\hline $\mathbf{R}$ & $\mathbf{P}_{\text {Value }}$ & حداقل & حداكثر & انحراف معيار & ميانكَين & متغير \\
\hline.$- \cdot 1 \cdot 91$ & . Ard & .119 & .194 & $\cdot 1 \cdot 1$ & - MET & زمان واكنش ساده (S) \\
\hline מTt & $\cdot / \cdot T \Lambda$ & $\cdot / 4 V$ & $\cdot \mid \wedge \varepsilon$ & $\cdot / 1$ & $\cdot \mid 4 \& \Lambda$ & زمان واكنش تشخيصى (S) \\
\hline$-\cdot|r \Delta|$ & $\cdot / \cdot r$ & $\cdot / 4 \pi$ & $\cdot / V r$ & $\cdot / \cdot \wedge \Lambda$ & . IFrA & زمان واكنش انتخابى رنتَها (s) \\
\hline$-\cdot / 49$ & $\cdot / \cdot r \Lambda$ & $\cdot / T V$ & $1 / 10$ & .11 & $\cdot / \& V$ & زمان واكنش انتخابى صداها (s) \\
\hline
\end{tabular}

جدول ه ارتباط احساس حرارتى ذهنى با تعداد خطاهاى يارامترهاى زمان واكنش را نشان مي دهد.

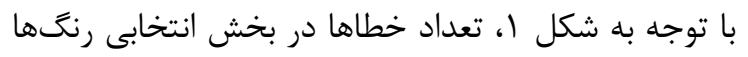
و تعداد خطاها در بخش انتخابى تشخيصى به ترتيب داراى لون بيشترين و كمترين ميانگين تعداد خطاها بودند
تعداد خطاها در بخش تشخيصى (r + •/ • (P=) و تعداد خطا

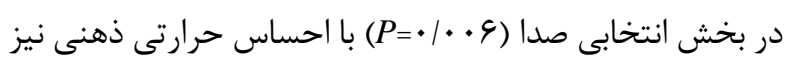
ارتباط معنادار منفى داشتند. ميانگين زمان واكنش بانش ساده

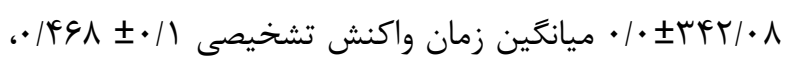

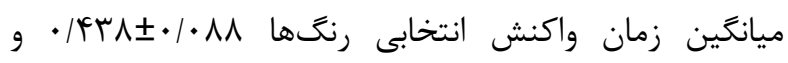

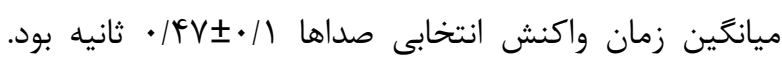


جدول ه. ارتباط احساس حرارتى ذهنى با تعداد خطاهاى يّارامترهاى زمان واكنش

\begin{tabular}{|c|c|c|c|c|}
\hline $\mathbf{R}$ & PValue & حداقل - & 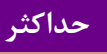 & 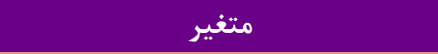 \\
\hline$-\cdot \mid F+1$ & $\cdot / \cdot r$ & • & $r$ & تعداد خطاها در بخش تشخيصى \\
\hline$-\cdot 11 \cdot 1$ & .109 & $\cdot$ & r & تعداد خطاها در بخش انتخابى رنكَها \\
\hline$-\cdot / r \vee s$ & $.1 \cdot .4$ & • & r & تعداد خطاها در بخش انتخابى صداها \\
\hline
\end{tabular}

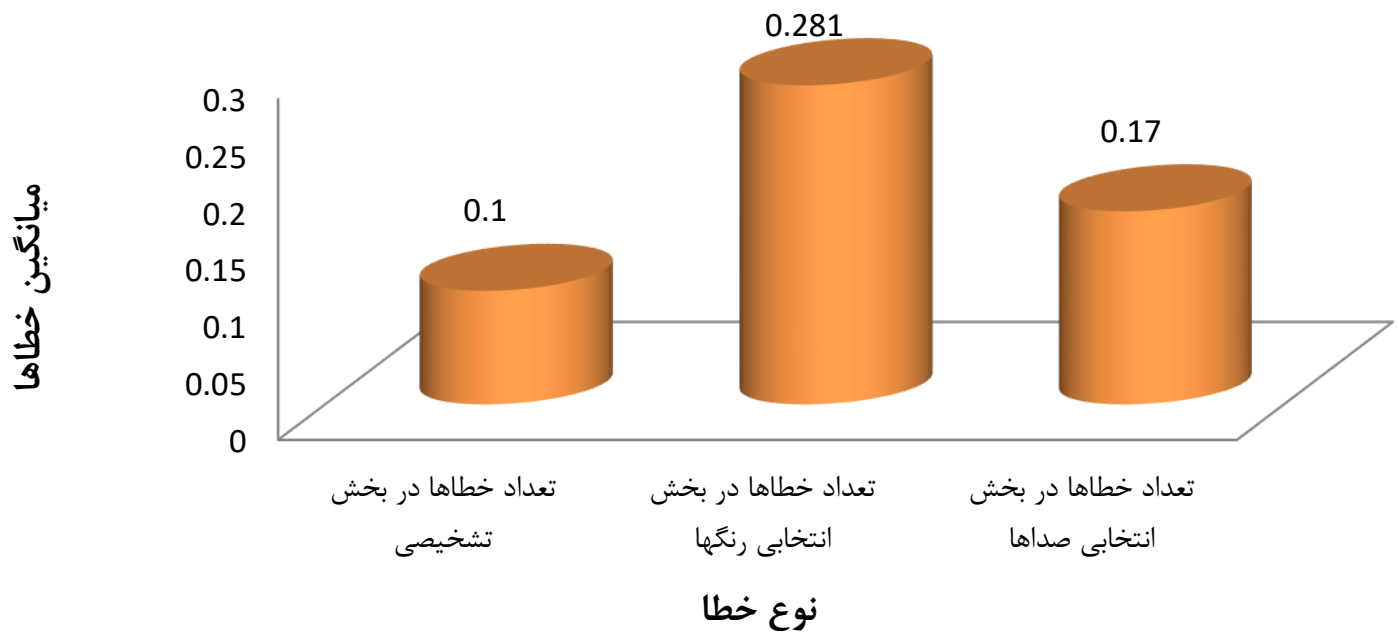

شكل 1. ميانغَين خطاهاى پارامتر هاى زمان واكنش

دارند و دانشجويان Q9/9 درصد استرس، س درصد اضطراب و

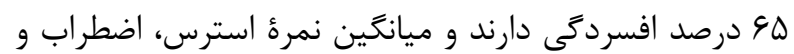

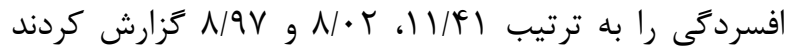

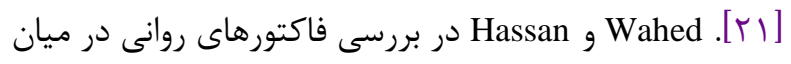
دانشجويان يزشكى نشان دادند، ميزان استرس، اضطراب و ورى

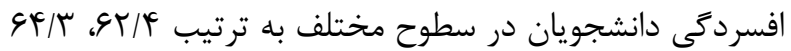

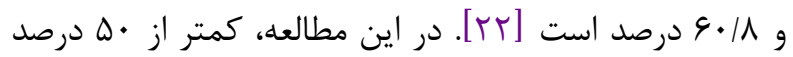

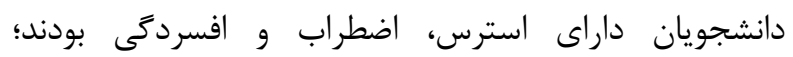
درحالى كه در مطالعات بيانشده بيش از • ه درصد دانشجويان،

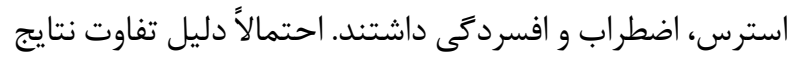
مطالعهُ حاضر با ساير مطالعات بيانشده اين است كه در

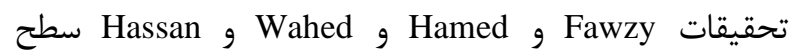
استرس، اضطراب و افسردگى در هر دو جنس زن و مرد بررسى

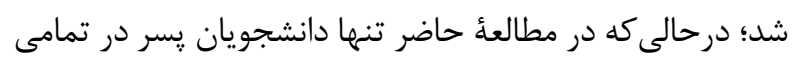

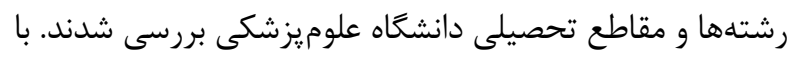
وجود اين، اين ميزان از استرس، اضطراب و افسردگى در در

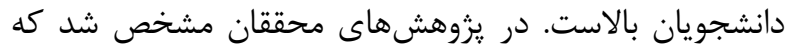

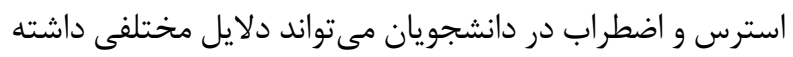

اين مطالعه با هدف تعيين احساس حرارتى ذهنى و ارتباط آن با

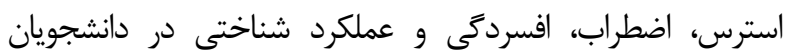
علوميزشكى انجام شد. يافتهها نشان مىدهد ميانگين دماى محيط

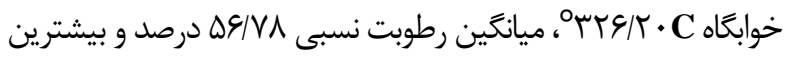
احساس حرارتى دانشجويان از دماى محيط اطراف خود در مقياس رئس خنتى به دست آمد كه با نتايج مطالعه گزارش كردند در مناطقى با آب و هواى گرمسيرى، سطح رطوبت بالا سبب كرايش افراد به سمت مقياس مثبت احساس حرارتى در فصل

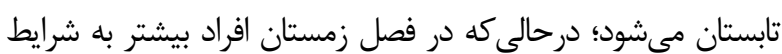

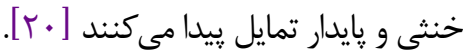
ميانگين نمره استرس، اضطراب و افسردگى در ميان دانشجويان به ترتيب درصد دانشجويان استرس در سطوح مختلف (خفيف، متوسط، شديد و خيلى شديد) داشتند. همجنين ست دانشجويان به ترتيب داراى اضطراب و افسردگى در سطوح مختلف بودند. Fawzy و Hamed نيز در بررسى سطح استرس، اضطراب و افسردىى دانشجويان گزارش كردند كه بيش از نيمى از جمعيت مورد بررسى در معرض عوامل آسيبزاى روانى قرار 
خنك و كمى خنك) بود، زمان واكنش آنان در بخش تشخيصى

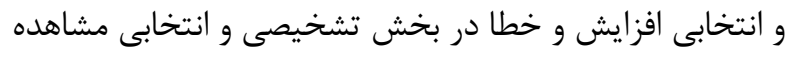
مىشد كه با نتايج مطالعه

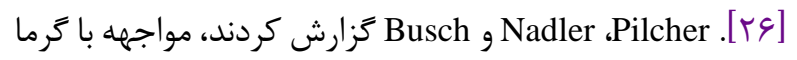
بر آزمون زمان واكنش مؤثر است. همجنين مواجهه با محيط

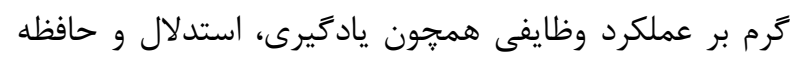

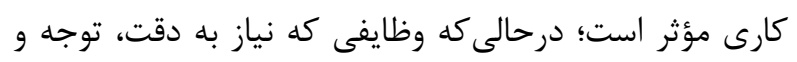

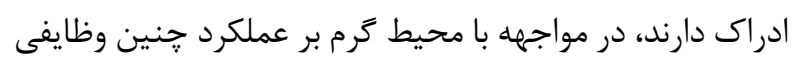

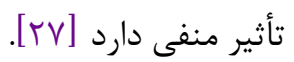

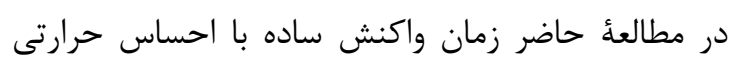

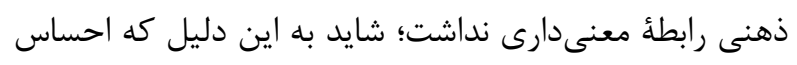

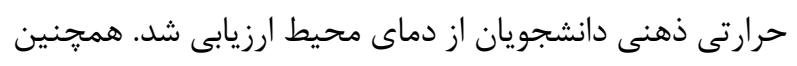

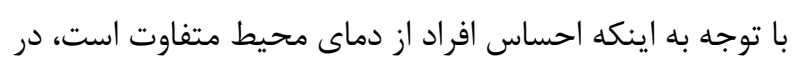

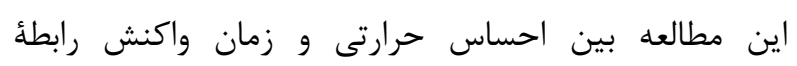

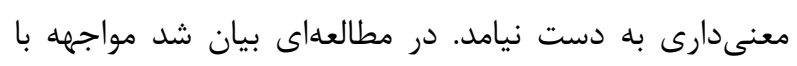

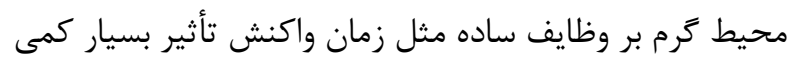

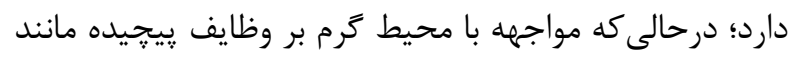

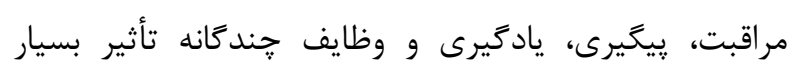

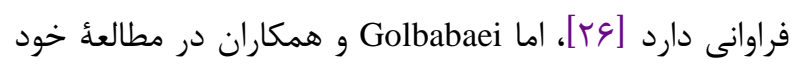

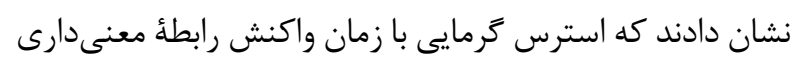

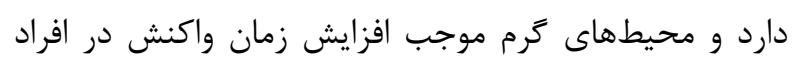

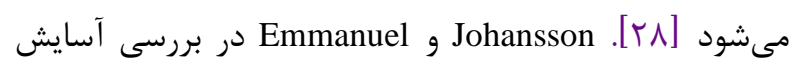

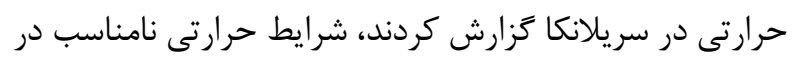

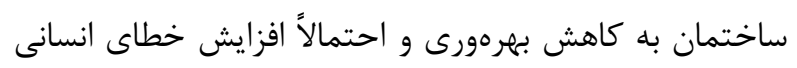
منجر مىشود. تنظيمات صحيح :ارامترهاى آسايش حرارتى كارنى

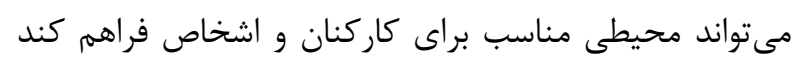

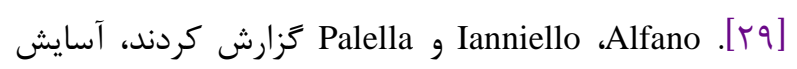
حرارتى در محيطهاى آموزشى بسيار مههم است و نبود آسايش

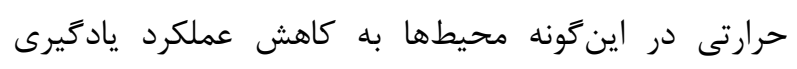

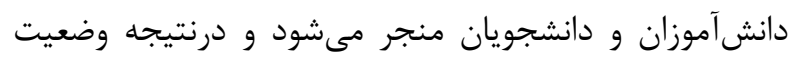

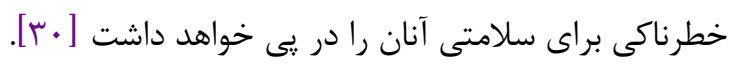

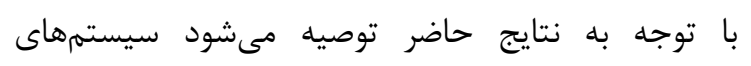

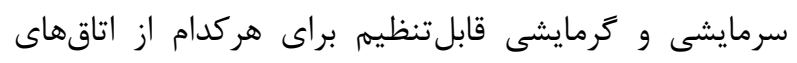

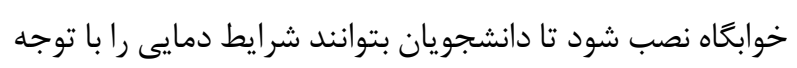

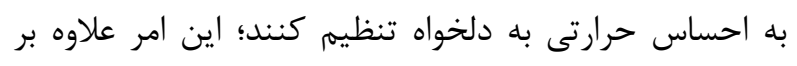

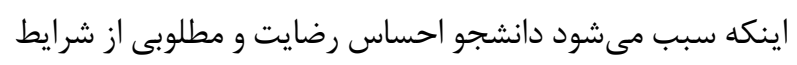

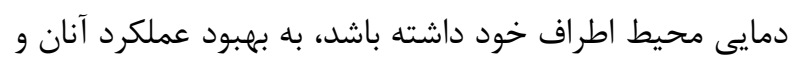
كاهش مصرف انرزى نيز منجر مى شود. از محدوديتهاى
باشد كه مىتوان به شرايط سنى، موقعيتهاى خاص اجتماعى،

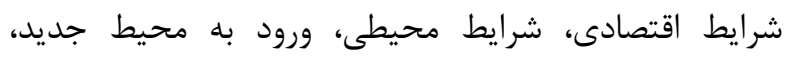

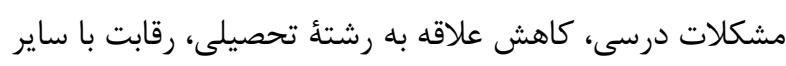

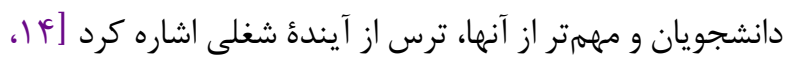

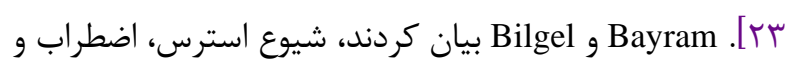

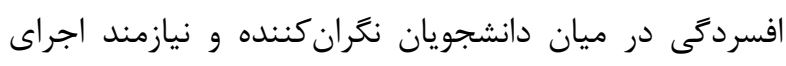

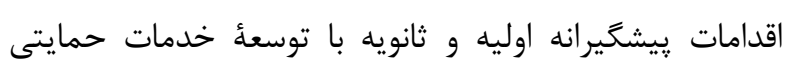

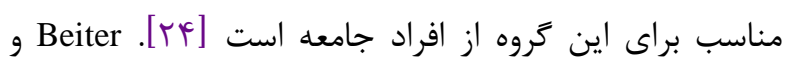

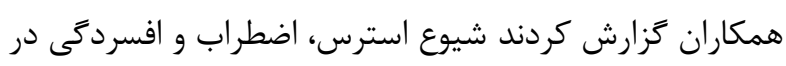

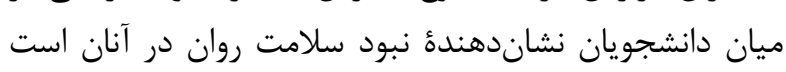

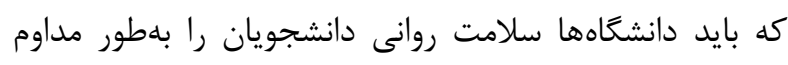

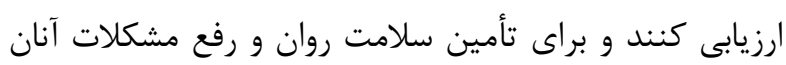

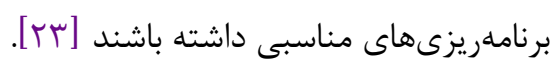
احساس حرارتى ذهنى دانشجويان با استرس و اضطراب رابطؤ

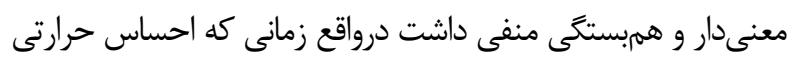

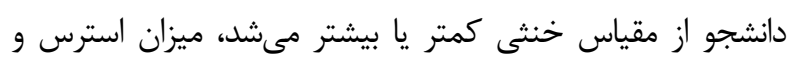

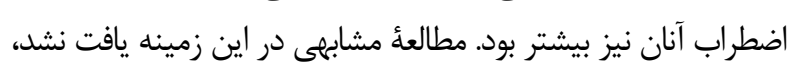

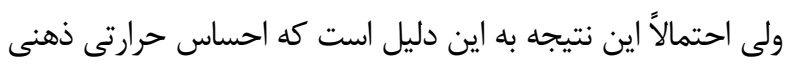

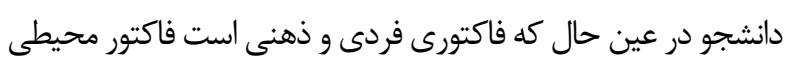

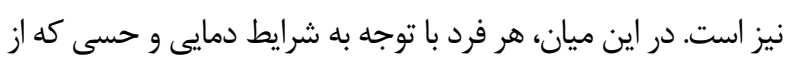

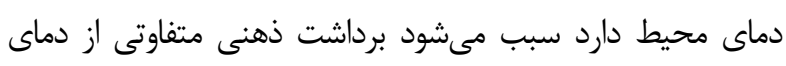

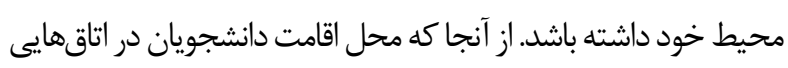

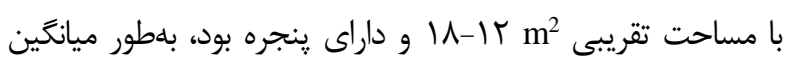

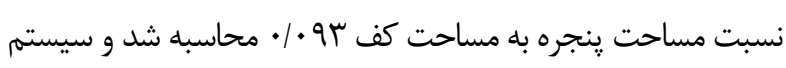

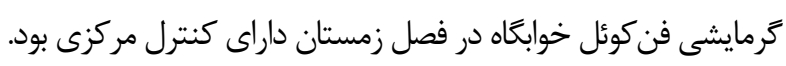

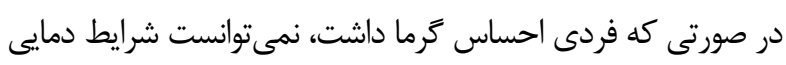

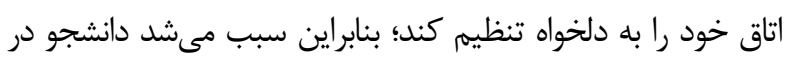

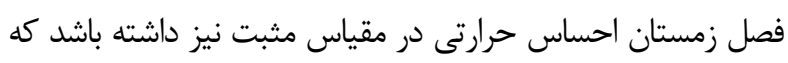

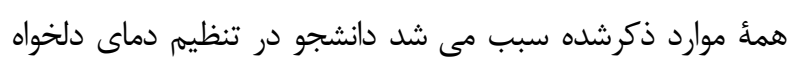

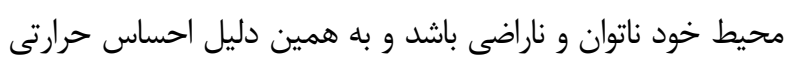

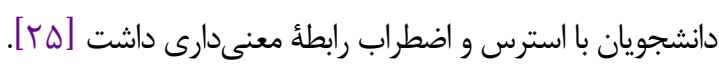

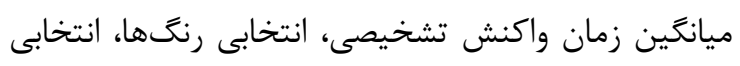

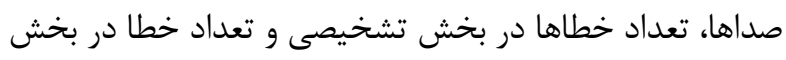

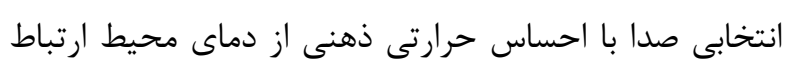

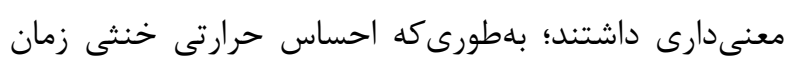

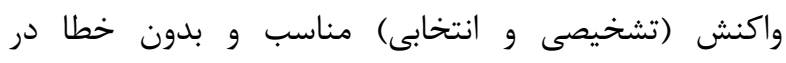

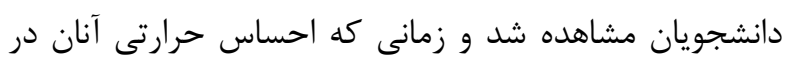

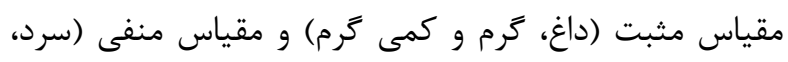


مدتزمان واكنش به محركها و تعداد خطاها افزايش مىيابد؛

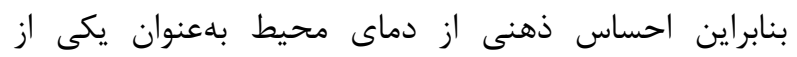

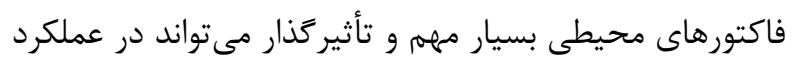

و كارايى دانشجويان نقش مهمى داشته باشد.

$$
\text { تقدير و تشكر }
$$

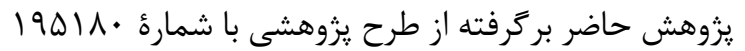
مصوب دانشگًاه علوم يزشكى اصفهان است. نويسندگًان

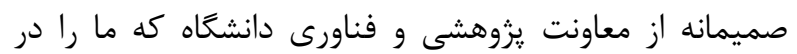
اجراى اين تحقيق يارى كردند، كمال تشكر و قدردانى را دارند.

$$
\text { تعارض منافع }
$$$$
\text { بين نويسندًان هيج تعارضى در منافع وجود ندارد. }
$$$$
\text { منابع مالى }
$$

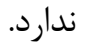

\section{References}

1. Ivanov M. Reliability of the results from unplanned subjective assessment of the indoor air quality and thermal comfort parameters in small lecture room. Energy Procedia. 2016;85:295-302. [DOI:10.1016/j.egypro.2015.12.255]

2. Mohamed S, Srinavin K. Forecasting labor productivity changes in construction using the PMV index. Int J Ind Ergon. 2005;35(4):345-51. [DOI:10.1016/j.ergon.2004.09.008]

3. Maiti R. PMV model is insufficient to capture subjective thermal response from Indians. Int $\mathbf{J}$ Ind Ergon. 2014;44(3):349-61.

[DOI:10.1016/j.ergon.2014.01.005]

4. Mendes A, Bonassi S, Aguiar L, Pereira C, Neves P, Silva S, Mendes D, Guimarães L, Moroni R, Teixeira JP. Indoor air quality and thermal comfort in elderly care centers. Urban Climate. 2015;14:486-501. [DOI:10.1016/j.uclim.2014.07.005]

5. Krüger EL, Zannin PH. Acoustic, thermal and luminous comfort in classrooms. Build Environ. 2004;39 (9):1055-63. [DOI:10.1016/j.buildenv.2004.01.030]

6. Tamm M, Jakobson A, Havik M, Burk A, Timpmann S, Allik J, Ööpik V, Kreegipuu K. The compression of perceived time in a hot environment depends on physiological and psychological factors. Quarterly J Experiment Psychol. 2014;67(1):197-208. [DOI: $10.1080 / 17470218.2013 .804849]$ [PMID]

7. McMorris T, Swain J, Smith M, Corbett J, Delves S, Sale C, Harris RC, Potter J. Heat stress, plasma
مطالعُ حاضر مى متوان به بررسىنكردن دانشجويان دختر، بررسىنكردن در ساير استانهاى كشور و بررسىنكردن در ساير فصول سال بهويره تابستان اشاره كرد؛ به همين دليل براى انجام

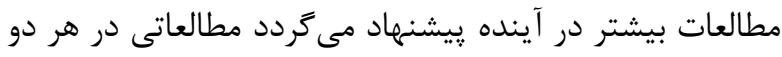
جنسيت زن و مرد، در محدوده جغرافيايى وسيعتر با شرايط آب دئن و هوايى متفاوت و ساير فصول سال بلويزه تابستان انجام شده و نتايج با يكديخر مقايسه شوند.

$$
\text { نتيجه گَيرى }
$$

كمتر از • ه درصد دانشجويان داراى استرس، اضطراب و

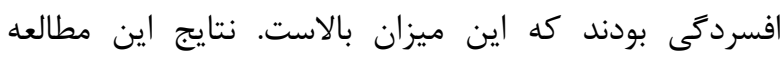
مشخص كرد، زمانى كه احساس حرارتى ذهنى دانشجويان از احساس حرارتى خنثى تهى باشد و در سطوح مختلف احساس رماسى

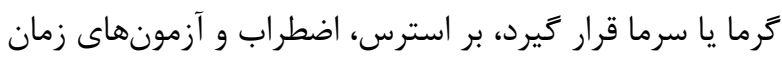
واكنش (زمان واكنش تشخيصى، زمان واكنش تشخيصى رنتها

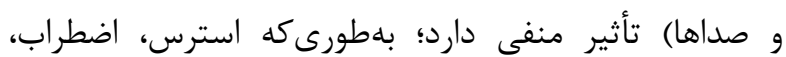

concentrations of adrenaline, noradrenaline, 5hydroxytryptamine and cortisol, mood state and cognitive performance. Int J Psychophysiol. 2006; 61(2):204-15. [DOI:10.1016/j.ijpsycho.2005.10.002] [PMID]

8. Abbasi M, Pourhossein M, Mohammadi H, Golbabaei F. A review on the effect of heat stresses on cognitive functions. JHSW. 2020;10(3):251-262.

9. Bar-Tal Y, Shrira A, Keinan G. The effect of stress on cognitive structuring: A cognitive motivational model. Personal Soc Psychol Rev. 2013;17(1):87-99. [DOI:10.1177/1088868312461309] [PMID]

10. Bucsuházy K, Semela M. Case study: Reaction time of children according to age. Procedia Eng. 2017;187:40813. [DOI:10.1016/i.proeng.2017.04.393]

11. Balazova I, Clausen G, Wyon DP. The influence of exposure to multiple indoor environmental parameters on human perception, performance and motivation. In Proceedings of CLIMA 2007.

12. Mihai $\mathrm{T}$, Iordache $\mathrm{V}$. Determining the indoor environment quality for an educational building. Energy Procedia. 2016;85:566-74. [DOI:10.1016/i.egypro.2015.12.246]

13. Badran DH, Al Ali MH, Duaibis RB, Amin WM. Burnout among clinical dental students at Jordanian universities. EMHJ-Eastern Mediterranean Health J. 2010; 16 (4), 434. [DOI:10.26719/2010.16.4.434] 
14. Ramazani S, Aramjoo H, Ramazani A, Hajipoor R, Naseri M. Survey of stress, anxiety and depression in paramedical students of Birjand University of Medical Sciences, 2016. Horizons Med Educ Dev. 2020;11(1):5-14.

15. Mohebian M, Dadashi M, Motamed N, Safdarian E. Evaluation of Depression, Anxiety, Stress levels and Stressors among Dental Students of Zanjan University of Medical Sciences in Academic Year of 2015. J Med Educ. 2017;10(26):108-22. [DOI:10.29252/edcj.10.26.60]

16. Gammon J, Morgan-Samuel H. A study to ascertain the effect of structured student tutorial support on student stress, self-esteem and coping. Nurse Educ Pract. 2005;5(3):161-71. [DOI:10.1016/j.nepr.2004.09.003] [PMID]

17. Jacquot CM, Schellen L, Kingma BR, van Baak MA, van Marken Lichtenbelt WD. Influence of thermophysiology on thermal behavior: the essentials of categorization. Physiology \& behavior. 2014; 128:180-7. [DOI:10.1016/j.physbeh.2014.01.025] [PMID]

18. Olesen BW, Parsons KC. Introduction to thermal comfort standards and to the proposed new version of EN ISO 7730. Energy Build. 2002;34(6):537-48. [DOI: 10.1016/S0378-7788(02)00004-X]

19. Pooravari M, Dehghani M, Salehi S, Habibi M. Confirmatory factor analysis of Persian version of Depression, Anxiety and Stress (DASS-42): Nonclinical sample. Razavi Int J Med. 2017;5(4).

20. Khan MH, Pao W. Thermal comfort analysis of PMV model prediction in air conditioned and naturally ventilated buildings. Energy Procedia. 2015;75:1373-9. [DOI:10.1016/i.egypro.2015.07.218]

21. Fawzy M, Hamed SA. Prevalence of psychological stress, depression and anxiety among medical students in Egypt. Psychiatry Res. 2017;255:186-94. [DOI:10.1016/i.psychres.2017.05.027] [PMID]

22. Wahed WY, Hassan SK. Prevalence and associated factors of stress, anxiety and depression among medical Fayoum University students. Alexandria J Med.
2017;53(1):77-84.

[DOI:10.1016/j.ajme.2016.01.005]

23. Beiter R, Nash R, McCrady M, Rhoades D, Linscomb M, Clarahan M, Sammut S. The prevalence and correlates of depression, anxiety, and stress in a sample of college students. J Affect Disord. 2015;173:90-6. [DOI:10.1016/j.jad.2014.10.054] [PMID]

24. Bayram N, Bilgel N. The prevalence and sociodemographic correlations of depression, anxiety and stress among a group of university students. Soc Psychiatry Psychiatr Epidemiol. 2008;43(8):667-72. [DOI:10.1007/s00127-008-0345-x] [PMID]

25. Ebrahimi H, Barakat S, Moradi B, Dehghan H, Sheykhdarani S. Assessment of Thermal Comfort within Dormitory of Isfahan University of Medical Sciences Based on ASHRAE Standard. Int J Occup Hyg. 2020;12(1):1-9.

26. Hancock PA, Vasmatzidis I. Effects of heat stress on cognitive performance: the current state of knowledge. International Journal of Hyperthermia. 2003 Jan 1;19(3):355-72. [DOI:10.1080/0265673021000054630] [PMID]

27. Pilcher JJ, Nadler E, Busch C. Effects of hot and cold temperature exposure on performance: a meta-analytic review. Ergonomics. 2002;45(10):682-98. [DOI:10.1080/00140130210158419] [PMID]

28. Golbabaei F, Mazloumi A, Mamhood Khani S, Kazemi Z, Hosseini M, Abbasinia M, Fahang Dehghan S. The effects of heat stress on selective attention and reaction time among workers of a hot industry: application of computerized version of stroop test. Health Safety Work. 2015;5(1):1-0.

29. Johansson E, Emmanuel R. The influence of urban design on outdoor thermal comfort in the hot, humid city of Colombo, Sri Lanka. Int J Biometeorol. 2006;51(2):119-33. [DOI:10.1007/s00484-0060047-6] [PMID]

30. Alfano FR, Ianniello E, Palella BI. PMV-PPD and acceptability in naturally ventilated schools. Build Environ. 2013;67:129-37. [DOI:10.1016/j.buildenv.2013.05.013] 